\title{
Computational Proteomics Analysis System
}

National Cancer Institute

\section{Source}

National Cancer Institute. Computational Proteomics Analysis System. NCI Thesaurus. Code C62487.

A suite of database and analysis tools for managing proteomics data; built on LabKey, the open source platform for science developed in partnership with the Fred Hutchison Cancer Research Center. 